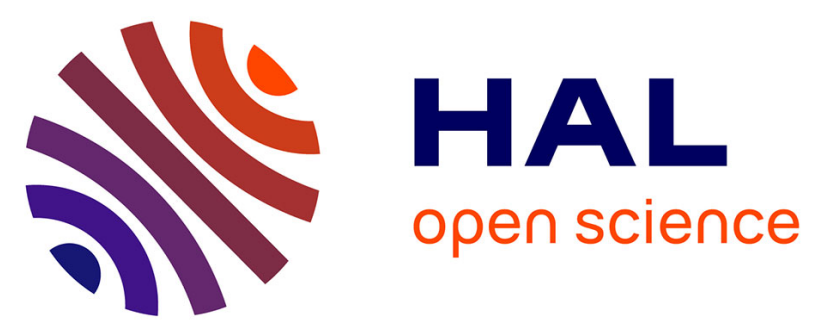

\title{
Fabrication of $\mathrm{Ti}$ substrate grain dependent $\mathrm{C} / \mathrm{TiO} 2$ composites through carbothermal treatment of anodic $\mathrm{TiO} 2$
}

\author{
Celine Rüdiger, Marco Favaro, Carlos Valero-Vidal, Laura Calvillo, Nathalie \\ Bozzolo, Suzanne Jacomet, Clivia Hejny, Luca Gregoratti, Matteo Amati, \\ Stefano Agnoli, et al.
}

\section{To cite this version:}

Celine Rüdiger, Marco Favaro, Carlos Valero-Vidal, Laura Calvillo, Nathalie Bozzolo, et al.. Fabrication of $\mathrm{Ti}$ substrate grain dependent $\mathrm{C} / \mathrm{TiO} 2$ composites through carbothermal treatment of anodic TiO2. Physical Chemistry Chemical Physics, 2016, 18 (13), pp.9220-9231. 10.1039/c5cp07727c . hal-01308669

\section{HAL Id: hal-01308669}

https://hal-mines-paristech.archives-ouvertes.fr/hal-01308669

Submitted on 28 Apr 2016

HAL is a multi-disciplinary open access archive for the deposit and dissemination of scientific research documents, whether they are published or not. The documents may come from teaching and research institutions in France or abroad, or from public or private research centers.
L'archive ouverte pluridisciplinaire HAL, est destinée au dépôt et à la diffusion de documents scientifiques de niveau recherche, publiés ou non, émanant des établissements d'enseignement et de recherche français ou étrangers, des laboratoires publics ou privés. 


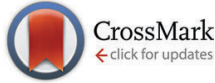

Cite this: Phys. Chem. Chem. Phys., 2016, 18, 9220

Received 15th December 2015 Accepted 28th February 2016

DOI: $10.1039 / c 5 c p 07727 c$

www.rsc.org/pccp

\section{Fabrication of Ti substrate grain dependent $\mathrm{C} / \mathrm{TiO}_{2}$ composites through carbothermal treatment of anodic $\mathrm{TiO}_{2} \dagger$}

\author{
Celine Rüdiger, $+^{*}{ }^{\mathrm{ab}}$ Marco Favaro, $\S^{\mathrm{c}}$ Carlos Valero-Vidal, $\boldsymbol{\uparrow}^{\mathrm{b}}$ Laura Calvillo, $^{\mathrm{c}}$ \\ Nathalie Bozzolo, ${ }^{d}$ Suzanne Jacomet, ${ }^{d}$ Clivia Hejny, ${ }^{e}$ Luca Gregoratti, \\ Matteo Amati, ${ }^{\mathrm{f}}$ Stefano Agnoli, ${ }^{\mathrm{C}}$ Gaetano Granozzi ${ }^{\mathrm{C}}$ and Julia Kunze-Liebhäuser* ${ }^{\mathrm{b}}$
}

\begin{abstract}
Composite materials of titania and graphitic carbon, and their optimized synthesis are highly interesting for application in sustainable energy conversion and storage. We report on planar $\mathrm{C} / \mathrm{TiO}_{2}$ composite films that are prepared on a polycrystalline titanium substrate by carbothermal treatment of compact anodic $\mathrm{TiO}_{2}$ with acetylene. This thin film material allows for the study of functional properties of $\mathrm{C} / \mathrm{TiO}_{2}$ as a function of chemical composition and structure. The chemical and structural properties of the composite on top of individual $\mathrm{Ti}$ substrate grains are examined by scanning photoelectron microscopy and micro-Raman spectroscopy. Through comparison of these data with electron backscatter diffraction, it is found that the amount of generated carbon and the grade of anodic film crystallinity correlate with the crystallographic orientation of the Ti substrate grains. On top of Ti grains with $\sim(0001)$ orientations the anodic $\mathrm{TiO}_{2}$ exhibits the highest grade of crystallinity, and the composite contains the highest fraction of graphitic carbon compared to Ti grains with other orientations. This indirect effect of the Ti substrate grain orientation yields new insights into the activity of $\mathrm{TiO}_{2}$ towards the decomposition of carbon precursors.
\end{abstract}

\section{Introduction}

Composite materials of titania and conductive graphitic carbon have gained particular research interest for application in photocatalysis, dye sensitized solar cells (DSSCs), Li-ion batteries and proton exchange membrane fuel cells (PEMFCs) due to the enhanced performance of the composite compared to $\mathrm{TiO}_{2}$ or $\mathrm{C}$ alone. ${ }^{1-5}$ It was shown that the application-specific performance of $\mathrm{C} / \mathrm{TiO}_{2}$ hybrid materials is highly sensitive to the synthesis route $^{6}$ and the detailed preparation conditions. ${ }^{1,7,8}$ There is evidence that the major benefits of functional $\mathrm{C} / \mathrm{TiO}_{2}$ nanocomposites, such as their superior stability and electric conductivity, rely on a close contact between conductive carbon and $\mathrm{TiO}_{2} \cdot{ }^{9,10}$ Hence, an adapted synthesis is of vital importance to optimize application-specific functional properties.

Biphasic $\mathrm{C} / \mathrm{TiO}_{2}$ or mixed $\mathrm{TiO}_{x} \mathrm{C}_{y}$ (rich in $\mathrm{TiC} / \mathrm{TiO}$ ) materials with different morphologies, such as nanotubes, nanoparticles or thin films, can be prepared via carbothermal treatment of initially prepared titania precursors with reactive acetylene $\left(\mathrm{C}_{2} \mathrm{H}_{2}\right)$ in a gas flow reactor. ${ }^{11-15}$ These materials have been tested as catalyst supports in studies of the electrochemical reduction of oxygen ${ }^{11}$ or oxidation of small alcohols, ${ }^{12,16,17}$ and as Li-ion battery anodes, ${ }^{15}$ and exhibited promising performances. The employed carbothermal route provides realistic process conditions that are relevant for the production of high surface area 
functional materials based on $\mathrm{TiO}_{2}$ and $\mathrm{C}$. The physico-chemical properties of the thus prepared materials are empirically tailored via the synthesis parameters. An adapted design of functional composites requires a detailed understanding of the correlation between the synthesis conditions and the intrinsic physicochemical properties of the produced materials.

In this context, planar anodic titania films that are carbothermally treated under reproducible conditions can be used to systematically study the synthesis-property-performance relationships, which are essential to identify the optimal synthesis procedure to obtain specific functional materials via the carbothermal route. Anodic films are particularly interesting due to their tunable morphology, which can be varied from compact films ${ }^{18}$ to high aspect ratio self-organized nanotubes. ${ }^{19}$ Several studies have been performed on carbothermally reduced compact anodic $\mathrm{TiO}_{2}$, rich in $\mathrm{TiO}$ and $\mathrm{TiC}$ phases, to correlate the synthesis conditions with intrinsic physico-chemical properties, such as structure and composition, and with functional performance, such as (electro-)chemical stability or electrical conductivity. ${ }^{14,16,17,20}$

In a previous study, we have shown that the synthesis conditions of $\mathrm{TiO}_{x} \mathrm{C}_{y}$ films ${ }^{14}$ significantly influence the catalytic activity of thereon deposited Pt nanoparticles towards the electro-oxidation of ethanol. Interestingly, it was found that the electrochemical stability of $\mathrm{Pt} / \mathrm{TiO}_{x} \mathrm{C}_{y}$ appeared to be affected by the grain orientations of the polycrystalline Ti substrate. ${ }^{16}$ This indicates that the texture of the Ti substrate, on which the precursor anodic film is prepared, constitutes an additional parameter that has to be taken into account when optimizing the synthesis of $\mathrm{TiO}_{x} \mathrm{C}_{y}$ films.

In view of the importance of $\mathrm{C} / \mathrm{TiO}_{2}$ composites for applications in energy conversion and storage, we present a study on the preparation of a thin carbon film on compact anodic $\mathrm{TiO}_{2}$ on polycrystalline $\mathrm{Ti}\left(\mathrm{C} / \mathrm{TiO}_{2} / \mathrm{Ti}_{\text {poly }}\right)$ by means of carbothermal treatment with $\mathrm{C}_{2} \mathrm{H}_{2}$ in a flow reactor at $550{ }^{\circ} \mathrm{C}$. A special focus is given to the investigation of the substrate grain dependent physico-chemical properties of the $\mathrm{C} / \mathrm{TiO}_{2}$ composite film.

The films are ex situ characterized by means of local analysis tools. Electron backscatter diffraction (EBSD), micro-Raman spectroscopy, scanning electron microscopy (SEM), atomic force microscopy (AFM) and scanning photoelectron microscopy (SPEM) are used to correlate grain orientations of the polycrystalline $\mathrm{Ti}$ substrate with the local crystalline phase composition, surface topography and chemical composition of the $\mathrm{C} / \mathrm{TiO}_{2}$ films.

The present study sheds light on the origin of the substrate grain effect in carburized $\mathrm{TiO}_{2} / \mathrm{Ti}_{\text {poly }}$ systems and thereby shows the significance of the $\mathrm{TiO}_{2}$ precursor properties for the synthesis of optimized functional $\mathrm{C} / \mathrm{TiO}_{2}$ composites via the carbothermal route.

\section{Experimental section}

Disks of $1 \mathrm{~mm}$ thickness and diameters of 10-15 $\mathrm{mm}$ were cut from a $20 \mathrm{~mm}$ diameter polycrystalline Ti rod (99.6\% purity, temper annealed, Advent Ltd, England). One side of the sample was mechanically and electrochemically polished, following the procedure described in ref. 14 (see the detailed description in the ESI $\dagger$ ). To enable the retrieval of identical spots on the samples, a cross-scratch was placed as a marker in the center of the electropolished area by using a tungsten needle.

The crystallographic texture of the electropolished Ti substrate was mapped by EBSD (see Fig. 1) using a FEI XL30 scanning electron microscope (SEM) operated at $20 \mathrm{kV}$ accelerating voltage and equipped with a TSL-EDAX EBSD system. The step size of the EBSD map was set to $2 \mu \mathrm{m}$, which led to a suitable spatial resolution of the microstructure.

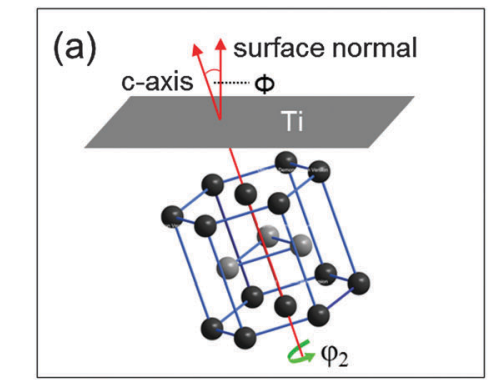

(b)
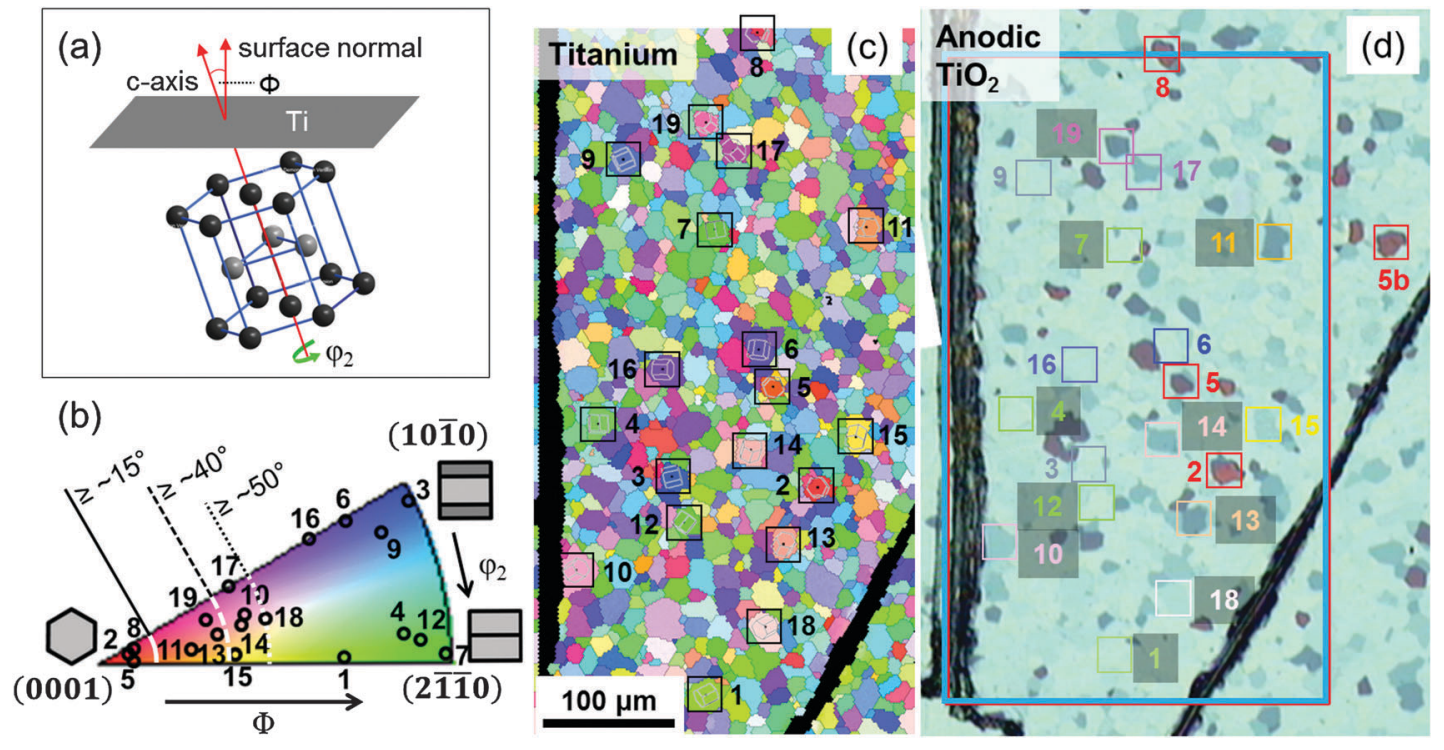

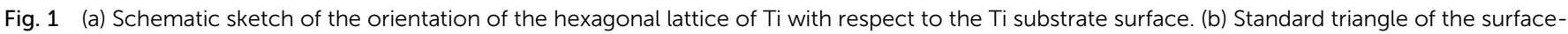

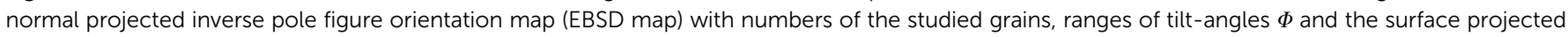
hexagonal cells. (c) EBSD map of a Ti substrate; (d) optical micrograph of the surface area shown in (c) after anodization. 
The electropolished Ti samples were consecutively cleaned in an ultrasonic bath with ethanol (technical grade), isopropanol (high purity) and de-ionized (DI) water (Millipore-Milli-Q system, 18.2 $\mathrm{M} \Omega$ ). Compact amorphous $\mathrm{TiO}_{2}$ films were produced by potentiostatic electrochemical anodization in a home-built Teflon electrochemical cell with a two-electrode configuration using a DC power supply controlled by a multimeter, and applying the following settings: anodization at $20 \mathrm{~V}$ for $600 \mathrm{~s}$ in $0.1 \mathrm{M}$ sulfuric acid $\left(\mathrm{H}_{2} \mathrm{SO}_{4}\right.$, analytical grade, 95-97\%, Merck, Germany) electrolyte at room temperature using a platinum mesh counter electrode. ${ }^{14}$ The anodic films were rinsed with DI water and dried in an argon (Ar 4.8, Linde, Germany) stream.

A carbon layer was synthesized on the anodic film by carbothermal treatment in a tubular quartz reactor under controlled gas flow. The gas flow and acetylene dose were optimized for the reactor geometry. In a reactor tube of $40 \mathrm{~mm}$ diameter, the following procedure was applied: [i] purged for two hours under a high flow of Ar to remove air, [ii] heated for up to $90 \mathrm{~min}$ at a constant rate to $550{ }^{\circ} \mathrm{C}$ in 200 standard cubic centimeters per minute (sccm) Ar, [iii] maintained for $60 \mathrm{~min}$ at $550{ }^{\circ} \mathrm{C}$, [iv] 0.5 flow $\%$ of acetylene $\left(\mathrm{C}_{2} \mathrm{H}_{2}\right.$, solvent-free, Linde, Germany) was added for $5 \mathrm{~min},[\mathrm{v}]$ maintained for $60 \mathrm{~min}$ at $550{ }^{\circ} \mathrm{C}$ in $\mathrm{Ar}$, and [vi] the oven was left to cool down to room temperature. These samples will be referred to as $\mathrm{C} / \mathrm{TiO}_{2}$. A reference sample (termed $\mathrm{TiO}_{2}^{\text {ref }}$ ) was thermally treated in $200 \mathrm{sccm}$ Ar without $\mathrm{C}_{2} \mathrm{H}_{2}$ according to the sequence [i]-[ii]-[v]-[vi].

After anodization and thermal treatment, optical micrographs were acquired for the reference sample using a camera of $10 \times$ magnification (belonging to the AFM equipment). The surface morphology of $\mathrm{TiO}_{2}$ and $\mathrm{C} / \mathrm{TiO}_{2}$ was investigated using a field emission SEM based on a GEMINI column in a Zeiss CrossBeam NVision 40 system. Micrographs were acquired with the in-lens secondary electron detector using an acceleration voltage of $4 \mathrm{kV}$ and working distances of 4-7 mm. AFM was performed as described in the ESI. $\dagger$

Micro-Raman spectroscopy was applied to investigate the crystalline phase composition of $\mathrm{C} / \mathrm{TiO}_{2}$ and $\mathrm{TiO}_{2}^{\text {ref }}$. A Jobin Yvon Horiba HR800 instrument equipped with a Nd:YAG laser $(532 \mathrm{~nm})$ was used in a non-focal operation mode and without a polarizer to analyze the average chemical composition and structure of the film on top of individual Ti substrate grains. The size of the focused laser spot on the sample was about $5 \mu \mathrm{m}$ using the $50 \times$ magnification of the optical microscope. Backscattered Raman signals were recorded with a resolution of less than $2 \mathrm{~cm}^{-1}$ (as determined by measuring the Rayleigh line) in a spectral range from 80 to $2000 \mathrm{~cm}^{-1}$.

SPEM was performed at the ESCAmicroscopy beamline at the Elettra Synchrotron Facility in Trieste, where the X-ray photon beam was demagnified by a Zone Plate to a sub-micron spot of about $150 \mathrm{~nm}$ onto the sample, which was then rastered to produce an image by detecting the photoelectrons generated from the sample. ${ }^{21}$ In this work the photon energy was set to $756 \mathrm{eV}$. The incident X-ray beam was normal to the sample surface while the angle between the hemispherical electron analyzer (HEA) and the sample surface was $30^{\circ}$. Photoelectron maps of $50 \times 50 \mu \mathrm{m}^{2}$ were recorded by sampling the surface with a step of $0.2 \mu \mathrm{m}$ and a dwelling time of $60 \mathrm{~ms}$ per pixel. The HEA was equipped with a multichannel electron detector which simultaneously acquires 48 maps (channels), each tuned to a specific photoelectron energy within a selected energy window. This allowed the (i) extraction of spectra from a selected area of the acquired photoelectron micrograph with an energy window of $7.8 \mathrm{eV}$ and a step of $0.164 \mathrm{eV}$ and (ii) removal of the topographic contributions to the photoelectron micrographs and extraction of the chemical contrast. The chemical contrast micrographs (chemical maps) were obtained by selecting, from the recorded 48 maps, those acquired at the photoelectron peak energy and those acquired at an energy related to the background of the photoelectron peak, integrating them to obtain two maps corresponding to the photoelectron peak and background intensity, and determining their ratio. ${ }^{22}$ The ratio of photoelectron maps acquired in the spectral regions of the $\mathrm{C} 1 \mathrm{~s}$ and $\mathrm{Ti} 2 \mathrm{p}$ core levels with their corresponding background is referred to as $\mathrm{C} / \mathrm{BG}$ and $\mathrm{TiO}_{2} / \mathrm{BG}$, respectively. For elemental analysis of the $\mathrm{C} / \mathrm{TiO}_{2}$ composite, the uncorrected absolute peak area was used as a qualitative measure, which was obtained from integration of the spectra from the image after subtraction of a constant background.

Additional information about the performed experiments can be found in the ESI. $\dagger$

\section{Results}

\subsection{Identification of substrate grain orientations}

The crystallographic orientations of the Ti substrate grains are determined by EBSD, which provides the three Euler angles, $\varphi_{1}$, $\Phi$ and $\varphi_{2}$, which define the crystallographic orientation of the hexagonal unit cell with respect to the substrate surface (according to the Bunge convention ${ }^{23}$ ). The sketch in Fig. 1 illustrates the orientation of the hexagonal lattice ${ }^{24}$ with respect to the substrate surface: $\Phi$ gives the tilt angle of the unit cell $c$-axis with respect to the surface normal and $\varphi_{2}$ gives the azimuthal rotation of the hexagonal unit cell around its $c$-axis. ${ }^{23,25}$ A rotation of the Ti substrate around its surface normal is described by the angle $\varphi_{1}$ (not shown in Fig. 1). The two Euler angles $\Phi$ and $\varphi_{2}$ can be restricted to $0^{\circ} \leq \Phi \leq 90^{\circ}$ and $0^{\circ} \leq \varphi_{2} \leq 30^{\circ}$ due to the symmetry of the hexagonal lattice. For the azimuthal rotation the zero point is chosen to coincide with the (1010) plane for $\Phi=90^{\circ}$, while $\varphi_{2}=30^{\circ}$ and $\Phi=90^{\circ}$ yield the (2īi 0$)$ plane. The crystallographic orientation of individual substrate grains can be illustrated in a surface-normal projected inverse pole figure orientation map (from now on termed EBSD map) like in Fig. 1c that uses an RGB color code defined in the standard triangle in Fig. 1b. From the colors in the standard triangle the crystallographic direction parallel to the sample surface normal can be deduced.

EBSD and optical microscopy are used to generate a correlation map between the Ti substrate grain orientation and the optical appearance of the anodic oxide film. Fig. 1 shows the EBSD map of an electropolished titanium substrate and an optical micrograph of the same surface after anodization. According to 
ellipsometry measurements (not shown), the fresh anodic $\mathrm{TiO}_{2}$ film has an average thickness of $\sim 53 \mathrm{~nm}$. The comparison of Fig. 1c and d reveals that the interference colors of the anodic $\mathrm{TiO}_{2}$ are strongly affected by the orientation of the Ti substrate grains. In particular, the substrate tilt angle $\Phi$ has an important impact on the optical properties of the oxide film. Variations in interference properties are directly related to variations in the $\mathrm{TiO}_{2}$ film thickness. Under the applied synthesis conditions, dark colors correspond to thinner films, and bright colors to thicker $\mathrm{TiO}_{2}$ films. ${ }^{26,27}$ We can define four ranges of substrate tilt angles $\Phi$ that cause different interference colors of the oxide film (see Fig. 1b). The azimuthal substrate orientation, described by $\varphi_{2}$, has only a minor effect on the interference colors of the anodic film (see ESI $\dagger$ ). Due to the rotational symmetry of the oxide film thickness on individual grains, the corresponding orientation angle $\varphi_{1}$ does not affect the interference color of the anodic $\mathrm{TiO}_{2}$. Table 1 summarizes the assignment of the oxide colors to the tilt angles $\Phi$ of the Ti substrate. This allows an estimation of the substrate orientations without the necessity of an EBSD measurement. The two orientations $\sim \operatorname{Ti}\{10 \overline{1} 0\}\left(\varphi_{2} \sim 0^{\circ}\right)$ and $\sim \operatorname{Ti}\{2 \overline{1} \overline{1} 0\}\left(\varphi_{2} \sim 30^{\circ}\right)$ can be deduced (without EBSD map) from the optical appearance of the anodic film after thermal treatment at $550{ }^{\circ} \mathrm{C}$ (see Fig. S1 and the discussion in ESI $\dagger$ ).

In the following, we will focus on the relationship of local chemical and physical properties, obtained by microscopic and spectroscopic techniques of planar $\mathrm{C} / \mathrm{TiO}_{2} / \mathrm{Ti}_{\text {poly }}$ composite materials, and the tilt angle $\Phi$ of the Ti substrate grains. The restriction to $\Phi$ is motivated by studies of the $\mathrm{TiO}_{2} / \mathrm{Ti}_{\text {poly }}$ system reported in the literature, which suggest that variations of the tilt angle $\Phi$ have a stronger influence on many physical and chemical properties of anodic $\mathrm{TiO}_{2}$ than the $c$-azimuthal orientation (given by $\left.\varphi_{2}\right) .^{25,28,29}$

\subsection{Thermal treatment with $\mathrm{C}_{2} \mathrm{H}_{2}$}

Fig. 2 shows top-view scanning electron micrographs of the as-grown anodic $\mathrm{TiO}_{2}$ and the $\mathrm{C} / \mathrm{TiO}_{2}$ composite film in the same surface area. On both films, the grain boundaries of the underlying Ti substrate are clearly visible. The crystallographic orientations of the substrate grains are indicated by surface projected hexagonal cells. The morphology of the anodic film varies for differently oriented substrate grains (Fig. 2b), which is a

Table 1 Assignment of crystallographic Ti substrate orientations to anodic $\mathrm{TiO}_{2}$ film colors

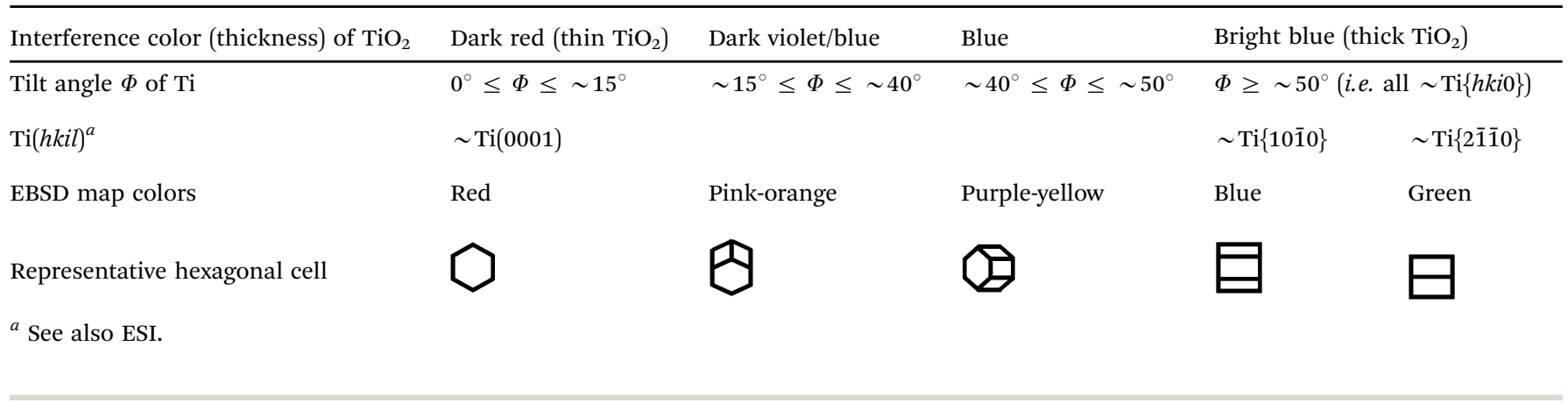

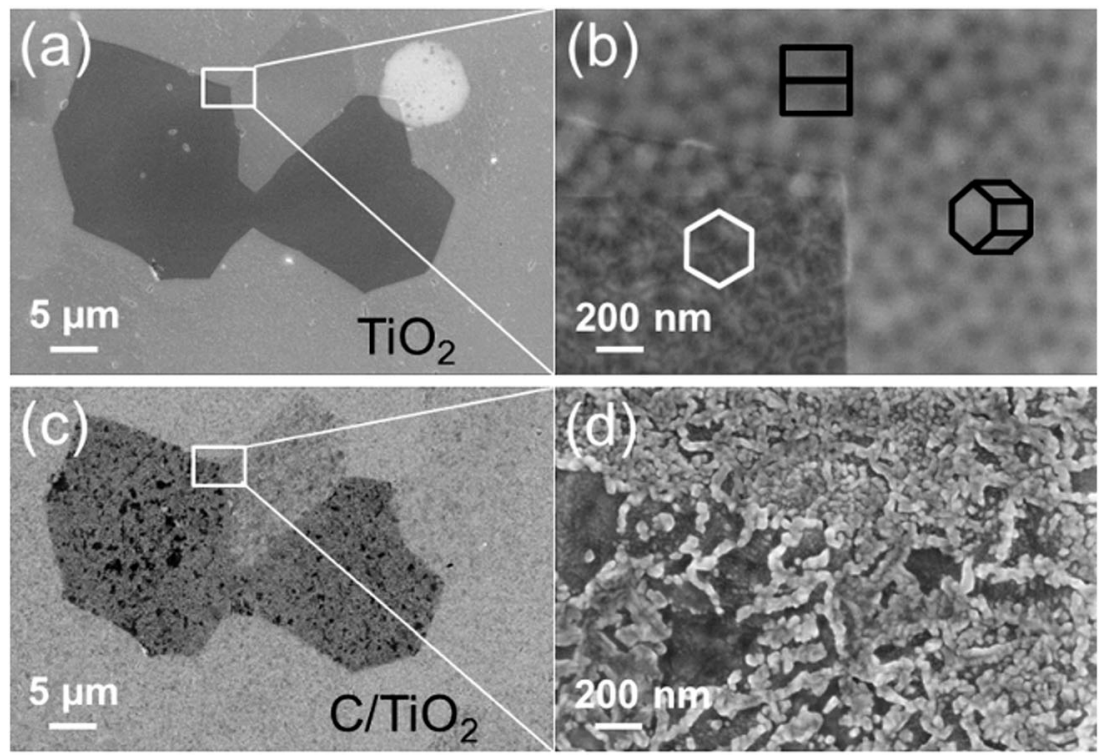

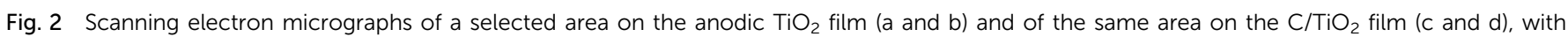
hexagonal cells representing the Ti substrate grain orientations. 
well-studied phenomenon. ${ }^{29}$ After the carbothermal treatment at $550{ }^{\circ} \mathrm{C}$, a granular film has formed on top of the anodic film (Fig. 2d). The morphology and the coverage of the deposit seem to be different on different substrate grains.

The crystalline phases and the chemical composition of the $\mathrm{C} / \mathrm{TiO}_{2} / \mathrm{Ti}_{\text {poly }}$ composite are determined using micro-Raman spectroscopy. The average Raman response of the film on top of single substrate grains is measured, since the focused laser beam has a lateral size of $\sim 5 \mu \mathrm{m}$, whereas the grains have a size of $10-20 \mu \mathrm{m}$. In the present case, the penetration depth is much larger than the $\mathrm{C} / \mathrm{TiO}_{2}$ film thickness (see discussion in the $\mathrm{ESI} \dagger$ ), therefore the Raman signal originates from the entire composite film. Fig. 3 shows micro-Raman spectra of $\mathrm{C} / \mathrm{TiO}_{2}$ for three ranges of $\mathrm{Ti}$ substrate tilt angles $\Phi$. To exclude contributions of carbon contamination from secondary sources, no EBSD map was obtained for the electropolished Ti surface of this sample. All six bands of first order Raman scattering of anatase $\mathrm{TiO}_{2}$ are detected between 100 and $830 \mathrm{~cm}^{-1}$ in the $\mathrm{C} / \mathrm{TiO}_{2}$ film. ${ }^{30}$ Due to the high proximity of the $\mathrm{A}_{1 \mathrm{~g}}$ band and the high frequency $B_{1 \mathrm{~g}}$ band, they appear as one peak at $\sim 517 \mathrm{~cm}^{-1}$. The weak shoulders at $320 \mathrm{~cm}^{-1}$ and $695 \mathrm{~cm}^{-1}$ can be attributed to combination bands of the anatase spectrum due to secondorder Raman scattering. ${ }^{30}$ The two most intense peaks of rutile, $\mathrm{E}_{\mathrm{g}}$ and $\mathrm{A}_{1 \mathrm{~g}}$, are present, as well as its most prominent combination band at $\sim 235 \mathrm{~cm}^{-1} \cdot{ }^{31}$ Peaks found at $\sim 267 \mathrm{~cm}^{-1}$ and

(a)

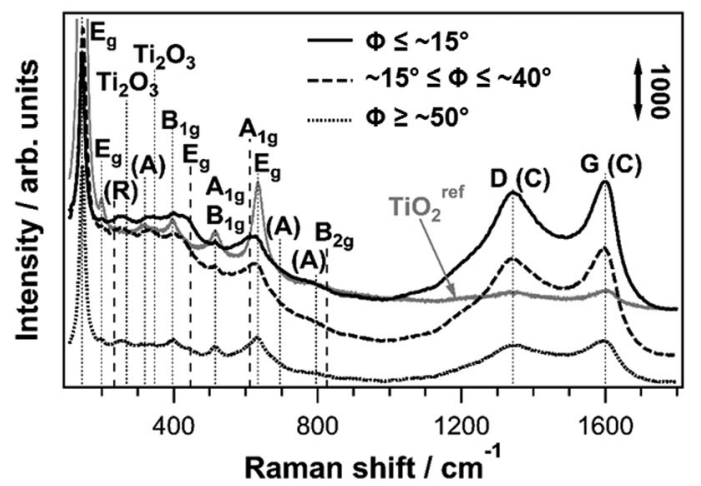

(b)

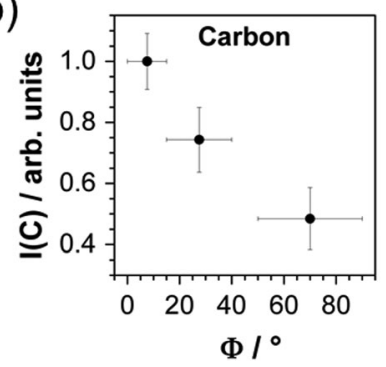

Fig. 3 (a) Micro-Raman spectra of $\mathrm{C} / \mathrm{TiO}_{2}$ on $\mathrm{Ti}_{\text {poly }}$ for different ranges of tilt angles $\Phi$. For clarity, the spectra are shifted vertically. $\mathrm{TiO}_{2}^{\text {ref. }}$ : the spectrum of the anodic $\mathrm{TiO}_{2}$ film on Ti with $\Phi \leq \sim 15^{\circ}$ after thermal treatment without $\mathrm{C}_{2} \mathrm{H}_{2}$. Dashed lines: rutile bands, dotted lines: all other bands. D- and G-bands: from carbon (C). $\mathrm{TiO}_{2}$ combination bands: $(\mathrm{R})=$ rutile, $(\mathrm{A})=$ anatase. (b) Integrated peak areas of carbon bands versus $\Phi$. Error bars of $/(C)$ : standard deviations of $/(C)$ on grains within one $\Phi$-range; error bars of $\Phi$ : ranges defined in Table 1. $\sim 347 \mathrm{~cm}^{-1}$ can be attributed to the most intense Raman signals of $\mathrm{Ti}_{2} \mathrm{O}_{3} \cdot{ }^{32,33}$ The broad features between $\sim 240$ and $\sim 395 \mathrm{~cm}^{-1}$ cannot be clearly identified. The Raman spectra reveal that the anodic $\mathrm{TiO}_{2}$ contains crystalline domains of anatase and rutile and is partially reduced after the carbothermal treatment with $\mathrm{C}_{2} \mathrm{H}_{2}$.

The spectra detected for different ranges of $\Phi$ clearly show that the phase composition of the film is affected by the underlying Ti substrate grain orientations. The fractions of crystalline anatase and rutile phases in the film can be deduced from the relative intensities of the corresponding Raman bands. ${ }^{34}$ A comparison between the most intense anatase $B_{1 g}$ band $\left(\sim 399 \mathrm{~cm}^{-1}\right)$ and the rutile $\mathrm{E}_{\mathrm{g}}$ band $\left(\sim 447 \mathrm{~cm}^{-1}\right)$, and between the rutile $\mathrm{A}_{1 \mathrm{~g}}$ band $\left(\sim 612 \mathrm{~cm}^{-1}\right)$ and the high frequency anatase $\mathrm{E}_{\mathrm{g}}$ band $\left(\sim 639 \mathrm{~cm}^{-1}\right)$ indicate that there is considerably more rutile present in the thermally treated anodic $\mathrm{TiO}_{2}$ film on top of grains with $\Phi \leq \sim 15^{\circ}$ than in the film on top of grains with $\Phi \geq \sim 50^{\circ}$. Grains with $\sim 15^{\circ} \leq \Phi \leq \sim 50^{\circ}$ exhibit mixed phase compositions.

All spectra depicted in Fig. 3 show two strong broad peaks at $\sim 1348$ and $\sim 1600 \mathrm{~cm}^{-1}$ that are the characteristic D- and G-bands of carbon and can be attributed to nanocrystalline graphite (NCG). ${ }^{35}$ The ratio of the D-band intensity to the G-band intensity is determined by means of a 4-peak Gaussian fit and yields values of $0.7-0.8$ independent of the substrate grain orientations (see Fig. S2 in the ESI $\dagger$ ), which correspond to NCG clusters of approximately $6 \mathrm{~nm}$ diameter according to the Tuinstra-Koenig relation. ${ }^{35}$

The carbon signal intensity appears to be influenced by the substrate grain orientation. In Fig. 3 the integrated and normalized areas of the Raman signals that correspond to vibrations of carbon, $I(\mathrm{C})$, are plotted versus the tilt angles $\Phi$ of the $\mathrm{Ti}$ substrate grains. $I(\mathrm{C})$ decreases markedly with increasing substrate tilt angle; on top of substrate grains with $\Phi \leq \sim 15^{\circ}$, the intensity is about 2 times higher than on top of substrate grains with tilt angles $\Phi \geq \sim 50^{\circ}$. The Raman response of the $\mathrm{C} / \mathrm{TiO}_{2}$ composite film differs considerably from the spectrum of a reference sample $\left(\mathrm{TiO}_{2}^{\text {ref }}\right)$ that underwent the same thermal treatment without the addition of $\mathrm{C}_{2} \mathrm{H}_{2}$ (see Fig. 3). The intensities of the carbon bands detected on $\mathrm{TiO}_{2}^{\text {ref }}$ are much lower than the ones detected on the $\mathrm{C} / \mathrm{TiO}_{2}$ composite, which evidences that the high amount of carbon in the latter originates from the decomposition of $\mathrm{C}_{2} \mathrm{H}_{2}$ and not from carbon contamination.

SPEM is performed on the $\mathrm{C} / \mathrm{TiO}_{2}$ composite to gain complementary information about the local chemical surface composition and its dependency on the Ti substrate grain orientation. The corresponding results are summarized in Fig. 4. Cross-correlation with EBSD allows for the assignment of crystallographic orientations to the $\mathrm{Ti}$ substrate grains underneath the anodic $\mathrm{TiO}_{2}$ film. It is important to note that only the region at the left of the dashed line in Fig. 4b coincides with the EBSD map that was acquired on the Ti substrate, which enables the identification of possible carbon contamination generated during the EBSD measurement. The grain labeled A in Fig. 4 belongs to substrate orientations with $0^{\circ} \leq \Phi \leq \sim 15^{\circ}$, whereas the grains labelled B and C are 

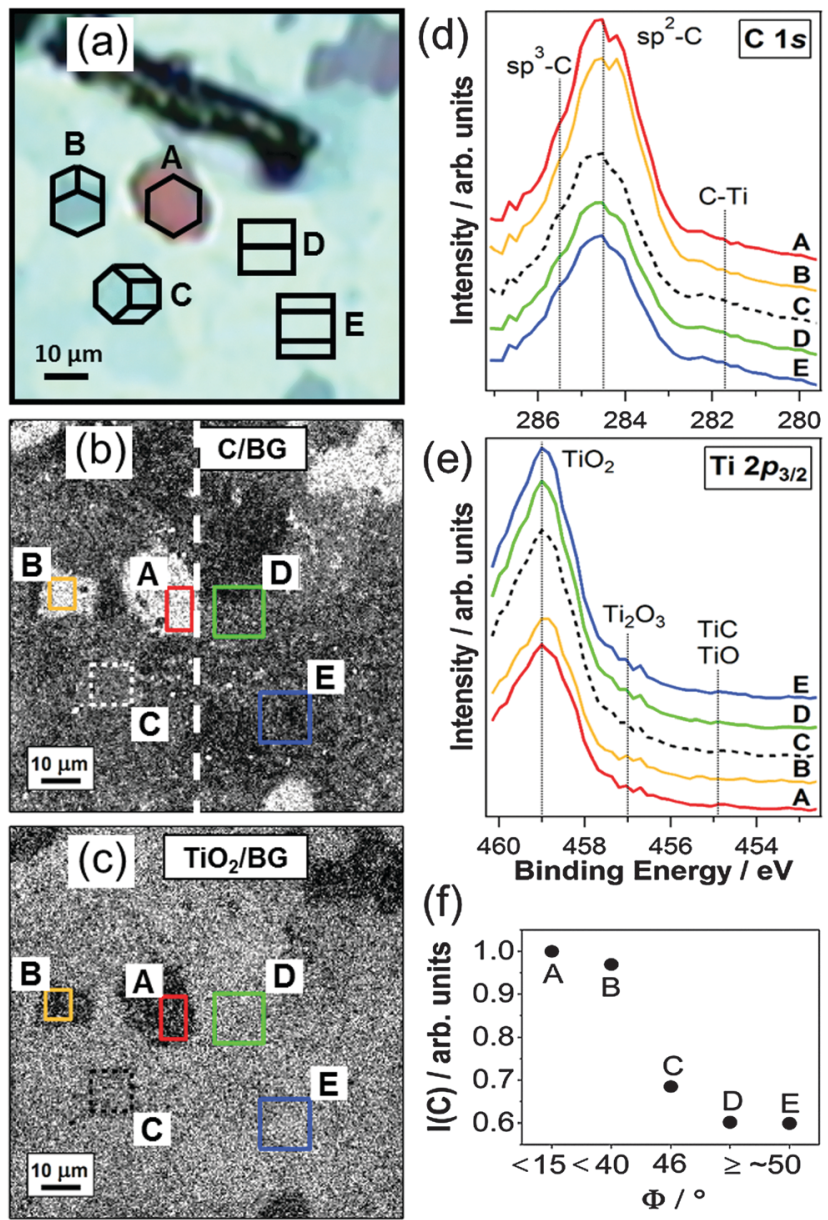

(f)

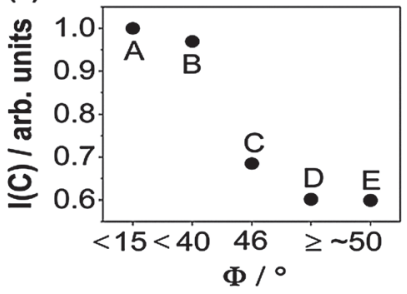

Fig. 4 (a) Optical micrograph of the anodic $\mathrm{TiO}_{2}$ film with surface projected hexagonal cells representing Ti substrate grain orientations (A-E). Chemical maps of the $C 1 \mathrm{~s}$ (b) and Ti $2 p_{3 / 2}$ (c) core levels obtained for the same film by SPEM after thermal treatment with $\mathrm{C}_{2} \mathrm{H}_{2}$ at $550{ }^{\circ} \mathrm{C}$. Spectra extracted from the boxes in the $\mathrm{C} 1 \mathrm{~s}$ (d) and the Ti $2 \mathrm{p}_{3 / 2}$ (e) chemical maps. For clarity, the spectra are shifted vertically. (f) Integrated $C$ 1s signal intensities, derived from (d), versus tilt angle $\Phi$ of Ti substrate grains.

characterized by underlying substrate tilt angles of $\sim 15^{\circ} \leq \Phi \leq$ $\sim 40^{\circ}$ and $\sim 40^{\circ} \leq \Phi \leq \sim 50^{\circ}$, respectively. Grains $\mathrm{D}$ and $\mathrm{E}$ correspond to substrate orientations with $\Phi \geq \sim 50^{\circ}$ (see hexagonal cells in Fig. 4a). From Fig. 4 it can be seen that the chemical composition of the carbothermally treated film surface is considerably affected by the properties of the Ti substrate grains. In the chemical map of Fig. $4 \mathrm{~b}$ brighter contrast corresponds to a relatively higher $\mathrm{C}$ 1s signal, evidencing an accordingly higher amount of carbon. In the same areas, the contrast in Fig. 4c appears darker. This can be explained by the presence of a thicker carbon layer on top of the anodic $\mathrm{TiO}_{2}$ film that attenuates the intensity of the $\mathrm{Ti} 2 \mathrm{p}$ core level photoelectrons. Interestingly, the film on grain $\mathrm{C}$, whose underlying Ti substrate is tilted by $\Phi=46^{\circ}$, appears to be just at the transition from high to low carbon content, since it is barely distinguishable from the surrounding area of the homogeneous shade in the chemical maps. No change in contrast can be observed across the dashed line in Fig. $4 \mathrm{~b}$, which proves the absence of artefacts caused by the acquisition of the EBSD map. Fig. $4 \mathrm{~d}$ and e report the $\mathrm{C} 1 \mathrm{~s}$ and $\mathrm{Ti} 2 \mathrm{p}_{3 / 2}$ spectra extracted from the indicated areas of the photoelectron micrographs. The $\mathrm{C}$ 1s peaks of all the studied grains are clearly dominated by the signal of graphitic carbon ( $\mathrm{sp}^{2}$ hybridized carbon), detected at $284.5 \mathrm{eV}^{36}$ This is in accordance with the Raman response of the $\mathrm{C} / \mathrm{TiO}_{2}$ composite, which proves the presence of NCG. The weak shoulder occurring at $285.6 \mathrm{eV}$ accounts for a small fraction of diamond-like carbon (DLC, $\mathrm{sp}^{3}$ hybridized carbon). ${ }^{20,36}$ No defined peak of carbidic carbon ( $\mathrm{C}-\mathrm{Ti}$ bonds) is found at $281.7 \mathrm{eV}$ (see Fig. S3 in the $\mathrm{ESI} \dagger$ ), hence only a negligible amount of this species is present at the $\mathrm{C} / \mathrm{TiO}_{2}$ interface. For all studied grains, the $\mathrm{Ti} 2 \mathrm{p}_{3 / 2}$ region is dominated by the $\mathrm{TiO}_{2}$ peak at $459 \mathrm{eV}^{20}$ that originates from the anodic film. The small shoulder at the low binding energy tail of the peak reveals the presence of reduced titania species, such as $\mathrm{Ti}(\mathrm{III})$ in $\mathrm{Ti}_{2} \mathrm{O}_{3}$ at $457 \mathrm{eV},{ }^{20}$ which confirms the Raman results. In accordance with the $\mathrm{C} 1 \mathrm{~s}$ spectrum, no pronounced $\mathrm{TiC}$ (or TiO) component is detected at $454.9 \mathrm{eV}$ in the $\mathrm{Ti} 2 \mathrm{p}$ spectrum (see Fig. S3 in ESI $\dagger$ ). Fig. 4f shows the variation of the integrated and normalized carbon signal intensities $I(\mathrm{C})$, extracted from the $\mathrm{C}$ 1s photoelectron micrograph, with substrate grain orientation, which gives an estimate of the differences in carbon content. As already indicated by the contrast in the chemical maps, there is an abrupt drop in the carbon intensity from grains with small tilt angles $\Phi$ (A, B) to grains with high tilt angles $\Phi(\mathrm{D}, \mathrm{E})$ and a transition between these two types of substrate grains represented by grain $\mathrm{C}$. The carbon signal intensity of grain $\mathrm{A}$ is about 1.7 times higher than the one of grain D. This trend is consistent with the Raman results (Fig. 3b). The complementary contrast in the chemical maps confirms a layered structure of the $\mathrm{C} / \mathrm{TiO}_{2}$ composite with a carbon film on top of the anodic $\mathrm{TiO}_{2}$.

In contrast, carbothermal treatment of anodic $\mathrm{TiO}_{2}$ films carried out in UHV and with different carbon precursors are reported to yield a conversion to TiO and TiC after shorter annealing times and lower temperatures. ${ }^{20,36}$ However, such $\mathrm{TiO}_{x} \mathrm{C}_{y}$ compact films were found to suffer from partial re-oxidation to $\mathrm{TiO}_{2}$ accompanied by the formation of graphitic carbon at the surface when exposed to ambient air. This was rationalized by DFT calculations which revealed that an increasing oxygen partial pressure favors the phase separation into graphitic carbon on top of anatase $\mathrm{TiO}_{2}{ }^{20}$ In the present study, the anodic films are treated with acetylene in a flow reactor with the supporting gas argon, which involves higher oxygen partial pressures than under UHV conditions. Thus it is likely that these conditions hinder the formation of $\mathrm{TiO}_{x} \mathrm{C}_{y}$ at $550{ }^{\circ} \mathrm{C}$ in favor of effective deposition of a carbon layer, or that only a low fraction of TiC and TiO species forms, which are easily re-oxidized upon exposure to air.

Since SPEM yields a photoelectron signal of $\mathrm{TiO}_{2}$ on all substrate grains, the maximum carbon layer thickness can be estimated from the probing depth for atomically planar graphitic carbon, which yields a thickness of about $2.3 \mathrm{~nm}$. A close look at the chemical maps reveals that the film on top of individual substrate grains has no perfectly homogeneous composition (see black spots on grain A in Fig. 4b), which is supported by the inhomogeneous coverage of the deposited 
film that is observed by SEM (Fig. 2d). This finding is most likely related to the properties of the anodic $\mathrm{TiO}_{2}$ at the moment that $\mathrm{C}_{2} \mathrm{H}_{2}$ interacts with it during the carbothermal treatment, which is described in the next section.

\subsection{Thermal treatment without $\mathrm{C}_{2} \mathrm{H}_{2}$}

During carbothermal treatment, $\mathrm{C}_{2} \mathrm{H}_{2}$ is added to the process after one hour of annealing at $550{ }^{\circ} \mathrm{C}$ under an argon gas flow. It can be expected that prior to the addition of $\mathrm{C}_{2} \mathrm{H}_{2}$, the properties of the anodic $\mathrm{TiO}_{2}$ film, in particular its crystallinity, are different from those of the pristine film and that these properties affect the interaction with $\mathrm{C}_{2} \mathrm{H}_{2}$. Hence, the investigation of the substrate grain dependent properties of the anodic $\mathrm{TiO}_{2}$ film prior to the addition of $\mathrm{C}_{2} \mathrm{H}_{2}$ may unravel the origin of the grain dependent chemical composition of the final $\mathrm{C} / \mathrm{TiO}_{2} / \mathrm{Ti}_{\text {poly }}$ composite. For this purpose, a reference sample ( $\left.\mathrm{TiO}_{2}^{\text {ref }}\right)$ was prepared under the same conditions as the $\mathrm{C} / \mathrm{TiO}_{2}$ composite, but the annealing treatment was stopped prior to the introduction of $\mathrm{C}_{2} \mathrm{H}_{2}$. An EBSD map of the polycrystalline Ti substrate recorded after electropolishing allows a precise identification of the tilt angles $\Phi$ of the grains.

Fig. 5a shows the Raman response of the $\mathrm{TiO}_{2}^{\text {ref }}$ film on individual substrate grains that exhibit different tilt angles $\Phi$. The colors of the spectra correspond to the substrate grain orientations that are indicated by black spots in the standard triangle (the studied grains are depicted in Fig. 1). Along the arrows, the tilt angle $\Phi$ of the substrate grains varies from $0^{\circ}$ to $90^{\circ}$. In all spectra the characteristic bands of first-order Raman scattering of crystalline anatase $\mathrm{TiO}_{2}$ are detected. The weak peaks at $320 \mathrm{~cm}^{-1}$ and $796 \mathrm{~cm}^{-1}$ are combination bands of anatase. ${ }^{30}$ Apart from a weak feature around $\sim 235 \mathrm{~cm}^{-1}$, no distinct peaks in the spectrum can be attributed to rutile, which suggests a very low fraction of this phase in the $\mathrm{TiO}_{2}^{\text {ref }}$ film. All spectra show two peaks at $\sim 1340$ and $\sim 1600 \mathrm{~cm}^{-1}$ that are the characteristic D- and G-bands of carbon, which indicate the presence of NGC. ${ }^{35}$

Fig. $5 \mathrm{~b}$ shows the spectra of an anodic $\mathrm{TiO}_{2}$ film on top of two different $\mathrm{Ti}$ substrate grains with $\Phi \geq \sim 50^{\circ}$ (i.e. grains belonging to the group of $\sim \operatorname{Ti}\{h k i 0\}$ orientations - see Table 1$)$ and $\Phi \leq \sim 15^{\circ}$ (i.e. $\sim \operatorname{Ti}(0001)$ ). Apart from the weakly protruding $\mathrm{E}_{\mathrm{g}}$ peak of anatase $\mathrm{TiO}_{2}$ at $143 \mathrm{~cm}^{-1}$, both Raman spectra are characterized by very broad and undefined features below $\sim 1000 \mathrm{~cm}^{-1}$, evidencing that the film is mainly amorphous. ${ }^{37-39}$ The intensity of the Raman signal of the $\mathrm{TiO}_{2}$ film on $\sim \mathrm{Ti}(0001)$ is slightly higher than that of the film on $\sim \mathrm{Ti}\{h k i 0\}$, which indicates that the grain orientation of the Ti substrate influences the properties of the pristine anodic $\mathrm{TiO}_{2}$ film on top. The comparison between the Raman response of the $\mathrm{TiO}_{2}^{\text {ref }}$ system and the pristine anodic $\mathrm{TiO}_{2}$ film discloses the changes that have occurred upon annealing: the thermal treatment at $550{ }^{\circ} \mathrm{C}$ leads to the crystallization of the anodic $\mathrm{TiO}_{2}$ film. No graphitic carbon is detected on the pristine anodic $\mathrm{TiO}_{2}$. The signal between 840 and $890 \mathrm{~cm}^{-1}$, however, could be assigned to the Raman active $\mathrm{C}-\mathrm{C}$ and $\mathrm{C}-\mathrm{O}$ stretching of organic carbon contamination. ${ }^{38-43}$ The carbon detected on $\mathrm{TiO}_{2}^{\text {ref }}$ may therefore originate from organic contamination adsorbed onto the surface of anodic

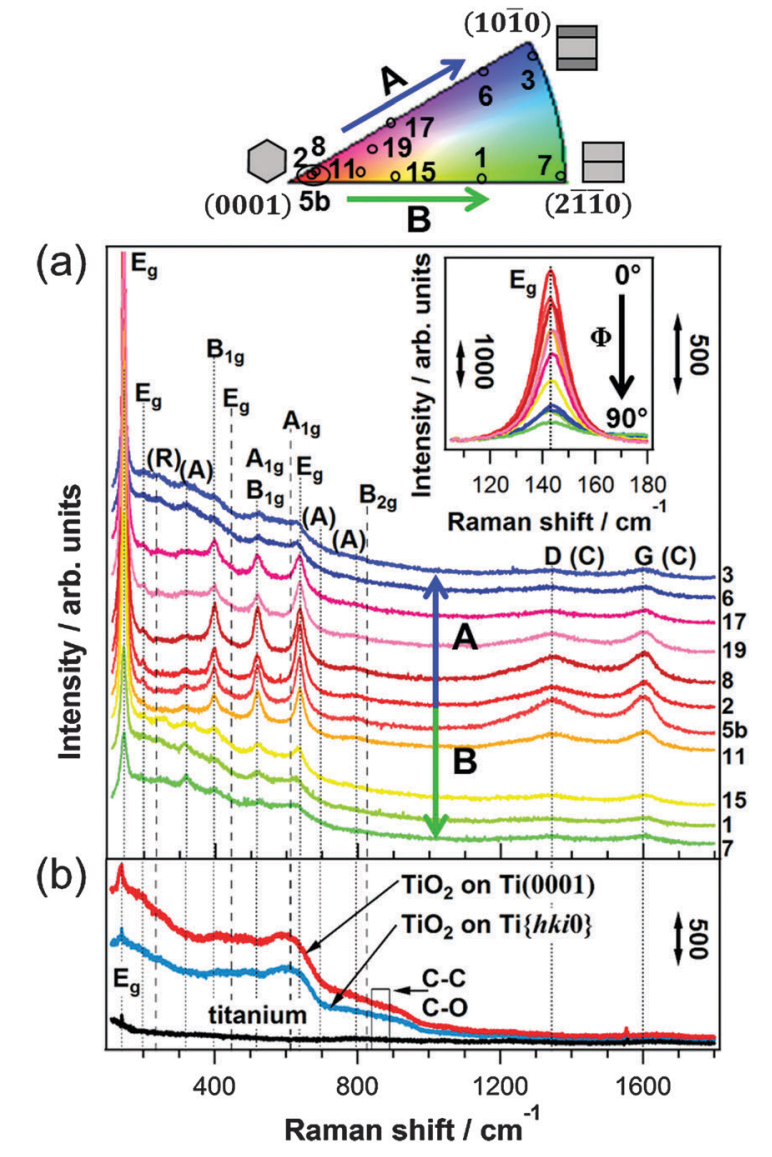

Fig. 5 (a) Micro-Raman spectra of $\mathrm{TiO}_{2}^{\text {ref }}$. For clarity the spectra are shifted vertically. Dashed lines: rutile, dotted lines: anatase, carbon. D- and G-bands: carbon (C). $\mathrm{TiO}_{2}$ combination bands: rutile (R), anatase (A). Inset: anatase $E_{g}$ peak $\left(143 \mathrm{~cm}^{-1}\right)$ evolution with tilt angle. Arrows (A and $\left.B\right)$ : directions of $\Phi$ variation from $0^{\circ}$ to $90^{\circ}$. (b) Micro-Raman spectrum of electropolished $\mathrm{Ti}$ (black) and an anodic $\mathrm{TiO}_{2}$ film on $\sim \mathrm{Ti}(0001)$ (red) and $\sim \mathrm{Ti}\{h k i 0\}$ (blue).

$\mathrm{TiO}_{2}$ and converted to graphitic carbon during the thermal treatment. An electropolished titanium substrate yields a flat baseline signal with almost no features (black spectrum in Fig. 5b). Only at around $143 \mathrm{~cm}^{-1}$ a small peak is detected which can be attributed to the corresponding $\mathrm{E}_{\mathrm{g}}$ band of anatase $\mathrm{TiO}_{2}$, arising most likely from the natural oxide film that is usually present on titanium. There is another small feature at about $1555 \mathrm{~cm}^{-1}$, which might originate from carbon contamination as well and which is also present on the anodic $\mathrm{TiO}_{2}$ film.

A strong influence of the substrate grain orientation on the Raman response of $\mathrm{TiO}_{2}^{\text {ref }}$ is found. While the anatase bands that are detected on top of grains with $\Phi \leq \sim 15^{\circ}$ (red spectra in Fig. 5a) are relatively intense and sharp, the same peaks are not only weaker and broader when detected on grains with $\Phi \geq \sim 50^{\circ}$ (green and blue spectra in Fig. 5a), but also embedded in a plateau-like background signal, which can be attributed to a considerable fraction of amorphous $\mathrm{TiO}_{2}$ in these films. Well-defined, intense Raman bands of narrow full width at half maximum (FWHM) are characteristic of an extended single crystal (see Fig. S4 in the $\mathrm{ESI} \dagger)^{30,44}$ and are hence an indication of high crystallinity of the detected anatase phase. The more 
intense the characteristic bands of anatase are, the higher is the fraction of this crystalline phase in the probed volume of $\mathrm{TiO}_{2}^{\mathrm{ref}}$. Peaks of small FWHM indicate a high long-range order and thus sufficiently large crystalline domains. The features of the amorphous $\mathrm{TiO}_{2}$ background are also present, but less pronounced, on grains with intermediate tilt angles, $\sim 15^{\circ} \leq \Phi \leq \sim 50^{\circ}$ (orange, yellow, light and dark purple spectra in Fig. 4a), suggesting that the anodic $\mathrm{TiO}_{2}$ film is partially crystalline on these grains. The crystallinity of the anatase phase gradually improves with decreasing $\Phi$, as can be inferred from the evolution of the $\mathrm{E}_{\mathrm{g}}$ band at $143 \mathrm{~cm}^{-1}$ (inset in Fig. 5a). A close comparison between the Raman spectra of grains 8,2 and 5b (red in Fig. 5a) reveals a variation in relative peak heights of the three characteristic anatase bands detected between 350 and $650 \mathrm{~cm}^{-1}$. This can be attributed to different preferential orientations of the anatase crystallites on these grains and is not related to varying crystallinity (see Fig. S4 and S5 and the discussion in the ESI $\dagger$ ).

Together with the improvement of crystallinity in the $\mathrm{TiO}_{2}^{\mathrm{re}}$ film, an increase in the intensity of the characteristic D- and G-bands of NCG is observed with decreasing $\Phi$. This suggests that the amount of produced graphitic carbon depends on the crystallinity of anodic $\mathrm{TiO}_{2}$, and in particular on its anatase content.

For a detailed analysis of the dependency of the $\mathrm{TiO}_{2}$ crystallinity and the carbon content on the substrate tilt angle, the low frequency $\mathrm{E}_{\mathrm{g}}\left(\sim 143 \mathrm{~cm}^{-1}\right)$, the $\mathrm{B}_{1 \mathrm{~g}}\left(\sim 396 \mathrm{~cm}^{-1}\right)$ and the high frequency $\mathrm{E}_{\mathrm{g}}\left(\sim 639 \mathrm{~cm}^{-1}\right)$ bands of anatase, as well as the Raman signal of carbon are fitted using Lorentzian and Gaussian line shapes (see Fig. S6 in the ESI $\dagger$ ). The fractions of the crystalline $\mathrm{TiO}_{2}$, the overall (i.e. crystalline and amorphous) $\mathrm{TiO}_{2}$ and the overall carbon phase in the film are then proportional to the integrated areas (i.e. intensities $I$ ) of the corresponding Raman signals (see ESI $\dagger$ ). To eliminate the possible effects of surface roughness of the $\mathrm{TiO}_{2}^{\text {ref }}$ film on the quantity of generated NCG, the carbon signal intensities are corrected for the topographic surface area $\left(I_{\text {spec }}(\mathrm{C})\right)$, which was determined by AFM (see Fig. S7 in the ESI $\dagger$ ). The obtained results are reported in Fig. 6.

The overall fraction of crystalline anatase stays almost constant and low for $\Phi \geq \sim 50^{\circ}$ and abruptly increases below $\Phi \sim 50^{\circ}$ to five times higher values (Fig. 6a). The intensities of the $B_{19}$ $\left(\sim 396 \mathrm{~cm}^{-1}\right)$ and the high frequency $\mathrm{E}_{\mathrm{g}}$ bands $\left(\sim 639 \mathrm{~cm}^{-1}\right)$ of anatase follow the same trends (see Fig. S8a in the ESI $\dagger$ ). In addition, a progressive blue-shift of the $\mathrm{B}_{1 \mathrm{~g}}$ band from $\sim 397$ to $\sim 402 \mathrm{~cm}^{-1}$ and a parallel red-shift of the $\mathrm{E}_{\mathrm{g}}$ band from $\sim 637$ to $\sim 628 \mathrm{~cm}^{-1}$ are observed when the tilt angle $\Phi$ increases from $0^{\circ}$ to $90^{\circ}$, which can be attributed to an increasing fraction of amorphous $\mathrm{TiO}_{2}$ (see Fig. S8b and $\mathrm{c}$ in the ESI $\dagger$ ).

The FWHM of the anatase $\mathrm{E}_{\mathrm{g}}$ band $\left(\sim 143 \mathrm{~cm}^{-1}\right)$ drops linearly with decreasing $\Phi$ (Fig. 6b). For anatase $\mathrm{TiO}_{2}$ nanocrystals, the FWHM of the $\mathrm{E}_{\mathrm{g}}$ band was reported to be inversely related to their dimensions. ${ }^{44-46}$ Hence, this trend indicates a continuous increase of the size of the crystalline anatase domains with decreasing $\Phi$. However, the smallest FWHM value of about $12 \mathrm{~cm}^{-1}$ is still higher than the value of $7 \mathrm{~cm}^{-1}$ that is expected for bulk anatase $\mathrm{TiO}_{2}$ (see Fig. S4 in the ESI $\dagger$ ). ${ }^{44,47}$ Therefore, the thermally treated anodic $\mathrm{TiO}_{2}$ film can be considered polycrystalline on top of every single substrate grain. Similar FWHM values (a)

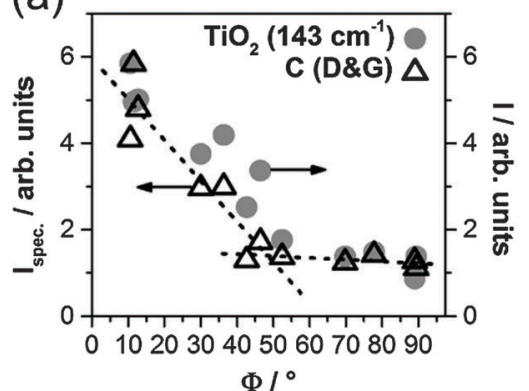

(b)

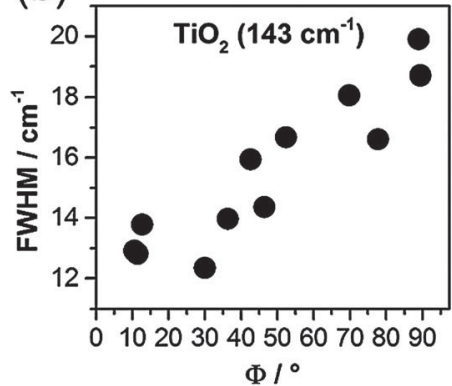

(c)

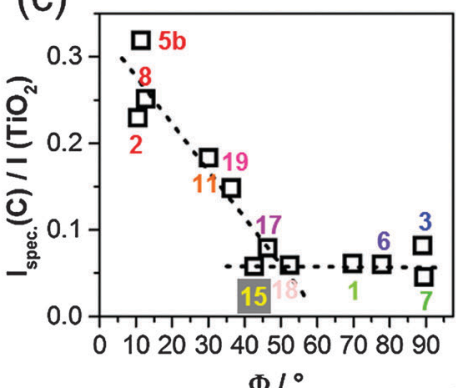

(d)

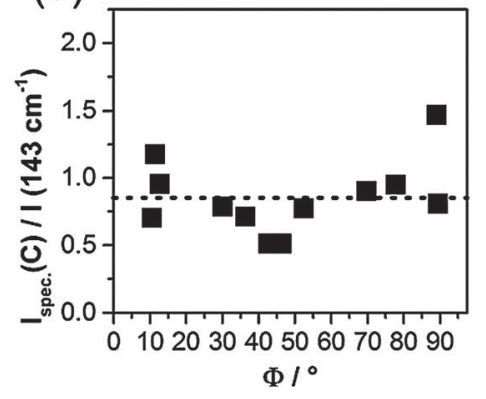

Fig. 6 Evaluation of Raman spectra of $\mathrm{TiO}_{2}^{\text {ref }}$ as a function of the substrate tilt angle $\Phi$. The studied grains are labeled with numbers and marked in the standard triangle. (a) Anatase $E_{g}$ band intensities at $\sim 143 \mathrm{~cm}^{-1}$ and area-specific carbon signal intensities $\left(I_{\text {spec }}(C)\right)$; (b) FWHM of the anatase $E_{g}$ band at $\sim 143 \mathrm{~cm}^{-1}$. (c) The ratio of $I_{\text {spec }}(\mathrm{C})$ and the overall Raman response of crystalline and amorphous $\mathrm{TiO}_{2}\left(/\left(\mathrm{TiO}_{2}\right)\right)$. (d) The ratio of $I_{\text {spec }}(\mathrm{C})$ and the intensity of the anatase $\mathrm{E}_{\mathrm{g}}$ band at $\sim 143 \mathrm{~cm}^{-1}$. Dashed lines in (a) and (c): linear least squares fits of carbon band intensities below $55^{\circ}$ and above $40^{\circ}$. Dashed line in (d): arithmetic mean $(0.85 \pm 0.27)$. 
were obtained for anatase $\mathrm{TiO}_{2}$ nanoparticles with a crystallite size of less than $\sim 20 \mathrm{~nm},{ }^{46}$ thus the domain sizes for thermally treated anodic $\mathrm{TiO}_{2}$ are in the nanometer range.

The area-specific carbon signal intensities, $I_{\mathrm{spec}}(\mathrm{C})$, give a qualitative measure of the amount of carbon on the thermally treated anodic film. From Fig. 6a it can be seen that $I_{\text {spec }}(\mathrm{C})$ follows the same trend with the substrate tilt angle as the intensity of the anatase $\mathrm{E}_{\mathrm{g}}$ band. In Fig. $6 \mathrm{c}, I_{\text {spec }}(\mathrm{C})$ is divided by the overall Raman response of $\mathrm{TiO}_{2}, \mathrm{I}\left(\mathrm{TiO}_{2}\right)$, (including the amorphous phase) on individual substrate grains. As in Fig. 6a, two regions of different slopes can be identified and the crossing of the corresponding least squares linear fits (dashed lines) yields the tilt angle $\Phi \sim 50^{\circ}$ as a threshold value. Below this point, $I_{\text {spec }}(\mathrm{C}) / I\left(\mathrm{TiO}_{2}\right)$ and therewith the amount of NCG that is produced on the $\mathrm{TiO}_{2}^{\text {ref }}$ upon thermal treatment is increased substantially. When $I_{\text {spec }}(\mathrm{C})$ is only divided by the intensity of the anatase $\mathrm{E}_{\mathrm{g}}$ band $\left(143 \mathrm{~cm}^{-1}\right)$, a plot versus $\Phi$ yields an almost constant line (Fig. 6d). This evidences that the two quantities, i.e. the amount of NCG and crystalline $\mathrm{TiO}_{2}$, are closely linked. The intensity ratio of the carbon bands is determined to be $0.7-0.8$, independent of the crystallographic orientations of the substrate grains underneath the film, which corresponds to NCG clusters of approximately $6 \mathrm{~nm}$ on the overall film (see ESI $\dagger$ ).

\section{Discussion}

\subsection{Crystallinity of the anodic film}

The phase evolution of anodic titania films during isothermal annealing proceeds from initially amorphous $\mathrm{TiO}_{2}$ to phasepure anatase, over mixed phases of anatase and rutile towards phase pure rutile $\mathrm{TiO}_{2}$, where the final phase composition depends on the annealing temperature, atmosphere and duration. ${ }^{38,39,48}$ A variation of the tilt angle $\Phi$ of the substrate grains from $\sim 50^{\circ}$ to $0^{\circ}$ appears to have the same effect on the final crystallinity of $\mathrm{TiO}_{2}^{\text {ref }}$ as an enhancement of annealing temperature. This implies that the substrate grain orientation, and in particular the tilt angle $\Phi$, has a strong impact on the kinetics of the phase transition. From the literature it is known that the compact anodic $\mathrm{TiO}_{2}$ on top of $\sim \mathrm{Ti}(0001)$ is thinner than on $\sim \operatorname{Ti}\{h k i 0\}$ and contains higher donor concentrations, i.e. oxygen vacancies. ${ }^{26,49,50}$ This is likely to affect the atomic reorganization or diffusion processes during annealing and therewith yield a higher isothermal crystallization rate for $\mathrm{TiO}_{2}$ on $\sim \mathrm{Ti}(0001)$ than for $\mathrm{TiO}_{2}$ on $\sim \mathrm{Ti}\{h k i 0\}$. In particular, a considerable increase of donor density, supported by a parallel increase in the electron transfer rate, oxygen evolution current and photocurrent, has been found for anodic $\mathrm{TiO}_{2}$ films on top of Ti substrate grains with tilt angles decreasing below $\Phi \sim 45^{\circ},{ }^{25,28}$ which is in very good agreement with the observed increase of $\mathrm{TiO}_{2}$ crystallinity for tilt angles $\Phi \leq \sim 50^{\circ}$ (see Fig. 6a).

The difference in phase composition of $\mathrm{TiO}_{2}^{\text {ref }}$ and $\mathrm{C} / \mathrm{TiO}_{2}$ is related to the annealing time, which is longer for the thermal treatment with $\mathrm{C}_{2} \mathrm{H}_{2}$, hence yielding a considerable fraction of rutile $\mathrm{TiO}_{2}$; in addition, the carbon present on the $\mathrm{TiO}_{2}$ may have an effect on the crystallization kinetics. ${ }^{51,52}$

\subsection{Carbon content in the $\mathrm{C} / \mathrm{TiO}_{2}$ composite}

SPEM, micro-Raman spectroscopy and SEM evidence that carbothermal treatment of a compact anodic $\mathrm{TiO}_{2}$ film with $\mathrm{C}_{2} \mathrm{H}_{2}$ at $550{ }^{\circ} \mathrm{C}$ yields a $\mathrm{C} / \mathrm{TiO}_{2}$ composite material, consisting of a few $\mathrm{nm}$ thick nanocrystalline graphitic carbon film on top of slightly reduced, polycrystalline $\mathrm{TiO}_{2}$. On the reference sample $\mathrm{TiO}_{2}^{\text {ref }}$, which is thermally treated without $\mathrm{C}_{2} \mathrm{H}_{2}$, a significantly less amount of carbon is detected, which originates from organic or hydrocarbon contamination of the anodic $\mathrm{TiO}_{2}$ only.

The carbon signal intensity, extracted from SPEM and microRaman spectroscopy, follows a very similar trend with $\Phi$ for both $\mathrm{TiO}_{2}^{\text {ref }}$ and $\mathrm{C} / \mathrm{TiO}_{2}$. There are mainly two classes of grains: class one comprises substrate grains with tilt angles of $0^{\circ} \leq \Phi \leq \sim 40^{\circ}$ where a relatively high amount of carbon is deposited on the oxide film; class two covers all grains with tilt angles $\Phi \geq \sim 50^{\circ}$ that exhibit a relatively low fraction of carbon after the carbothermal treatment of the anodic $\mathrm{TiO}_{2}$. Grains with $\sim 40^{\circ} \leq \Phi \leq$ $\sim 50^{\circ}$ belong to a transition zone, where an orientation of $\Phi \sim 50^{\circ}$ can be identified as a threshold value.

The nature of the carbon film found on $\mathrm{TiO}_{2}^{\mathrm{ref}}$ and $\mathrm{C} / \mathrm{TiO}_{2}$ is very similar, as evidenced by the resembling shapes of the Raman responses of carbon: the evaluation of the carbon bands' intensity ratios yields a NCG cluster size of approximately $6 \mathrm{~nm}$, independent of the substrate grain orientation and the carbon source.

The formation of a grain-dependent carbon layer under the applied carbothermal treatment strongly suggests that $\mathrm{C}_{2} \mathrm{H}_{2}$ (and even organic contamination) is not thermally but catalytically decomposed at the surface of $\mathrm{TiO}_{2} \cdot{ }^{53}$ Furthermore, the presented results evidence that crystalline $\mathrm{TiO}_{2}$, in particular the anatase phase, is able to decompose $\mathrm{C}_{2} \mathrm{H}_{2}$, since only a small amount of carbon is found on $\mathrm{TiO}_{2}$ that is mainly amorphous. It has been reported that $\mathrm{Ti}^{4+}-\mathrm{O}^{2-}$ Lewis acid-base pairs on the surface of crystalline $\mathrm{TiO}_{2}$ are the active centers for a heterolytic dissociation of $\mathrm{C}_{2} \mathrm{H}_{2}$ initiating self-assembly processes of acetylene to form polycyclic aromatic hydrocarbons at room temperature and graphitic carbon at sufficiently high temperatures $\left(650{ }^{\circ} \mathrm{C}\right.$ in ref. 53). ${ }^{54,55}$ Anatase $\mathrm{TiO}_{2}$ was found to be particularly efficient for the decomposition of acetylene, which is in line with our findings.

The crystallinity of compact anodic films on polycrystalline Ti substrates is affected by the Ti substrate grain orientations. This causes the observed grain dependent average chemical surface composition of the obtained $\mathrm{C} / \mathrm{TiO}_{2}$ composite. In a previous in situ study on the conversion of anodic $\mathrm{TiO}_{2} / \mathrm{Ti}_{\text {poly }}$ into $\mathrm{TiO}_{x} \mathrm{C}_{y} / \mathrm{Ti}_{\text {poly }}$ under UHV conditions, a substrate grain dependent chemical composition of the final $\mathrm{TiO}_{x} \mathrm{C}_{y}$ film was found, evidencing that also under different synthesis conditions (temperature, pressure, and carbon source), effects of the polycrystalline substrate need to be taken into account. ${ }^{20}$ A detailed investigation of the temperature-dependence of the surface chemistry and the structure of this system is ongoing and will be published separately.

From the FWHM values of the anatase $\mathrm{E}_{\mathrm{g}}\left(143 \mathrm{~cm}^{-1}\right)$ bands it is deduced that the $\mathrm{TiO}_{2}^{\text {ref }}$ film consists of polycrystalline anatase with nanometer size crystallites. This may explain why 
only nanocrystalline and no extended graphitic carbon layers are formed in the course of the thermal treatment. Furthermore, it gives an explanation for the inhomogeneous carbon coverage of $\mathrm{TiO}_{2}$ on individual substrate grains as observed with SPEM and SEM, which is particularly emphasized on top of grains that are tilted by $\Phi \leq \sim 15^{\circ}$ : a polycrystalline $\mathrm{TiO}_{2}$ film consists of anatase domains that have different orientations exposing different faces at the surface, which in turn affects their activity towards $\mathrm{C}_{2} \mathrm{H}_{2}$ decomposition. The reason for this is that different anatase faces exhibit different fractions of active $\mathrm{Ti}^{4+}-\mathrm{O}^{2-}$ centers. According to the literature a high fraction of these sites appears to be present on dehydroxylated, stoichiometric and extended (001) and/or (010) planes of crystalline anatase. ${ }^{5,56}$

Our results demonstrate that the peculiar properties of compact anodic $\mathrm{TiO}_{2}$ films on $\mathrm{Ti}_{\text {poly }}$ have an important impact on the synthesis of $\mathrm{C} / \mathrm{TiO}_{2} / \mathrm{Ti}_{\text {poly }}$ composites via the carbothermal route. The obtained substrate grain dependent chemical composition and structure of the film is likely to affect its overall performance when applied in electrocatalysis or Li-ion battery studies. For example, it is known that local variations in the charge transfer kinetics play a crucial role in the overall activity of electrocatalysts. ${ }^{57}$ The grain dependent electrochemical stability of $\mathrm{Pt} / \mathrm{TiO}_{x} \mathrm{C}_{y}$ found in ref. 16 is another consequence of these properties of anodic $\mathrm{TiO}_{2}$ on $\mathrm{Ti}_{\text {poly }}$. An adapted design of $\mathrm{C} / \mathrm{TiO}_{2}$ films requires a detailed knowledge of the substrate texture and a controlled crystallization of the anodic film during the carbothermal treatment. The presence of crystalline anatase $\mathrm{TiO}_{2}$ required for the reactive decomposition of $\mathrm{C}_{2} \mathrm{H}_{2}$ at $550{ }^{\circ} \mathrm{C}$ and atmospheric pressure has implications on the carbothermal synthesis of functional $\mathrm{C} / \mathrm{TiO}_{2}$ materials in general.

\section{Conclusions}

In the present work the substrate grain dependent properties of planar $\mathrm{C} / \mathrm{TiO}_{2} / \mathrm{Ti}_{\text {poly }}$ composite films that are synthesized via carbothermal treatment of compact anodic $\mathrm{TiO}_{2}$ with $\mathrm{C}_{2} \mathrm{H}_{2}$ in a flow reactor at $550{ }^{\circ} \mathrm{C}$ have been investigated. A pronounced correlation between the amount of deposited carbon and the Ti substrate grain orientations is observed: a significantly high amount of graphitic carbon is deposited on the anodic $\mathrm{TiO}_{2}$ film on top of $\sim \mathrm{Ti}(0001)$ grains than on $\mathrm{TiO}_{2}$ on top of $\sim \mathrm{Ti}\{h k i 0\}$ grains. The origin of the grain effect is identified as a substrate grain-dependent crystallization of the initially amorphous anodic $\mathrm{TiO}_{2}$ film to nanocrystalline anatase during the thermal treatment, which in turn affects the activity of $\mathrm{TiO}_{2}$ towards $\mathrm{C}_{2} \mathrm{H}_{2}$ decomposition to form nanocrystalline graphite. This effect emphasizes the importance of $\mathrm{TiO}_{2}$ precursor crystallinity for the synthesis of $\mathrm{C} / \mathrm{TiO}_{2}$ functional materials via a carbothermal route. In the case of anodic $\mathrm{TiO}_{2}$ films, the crystallization needs to be guided towards extended single crystalline anatase domains exposing their most active facets to enable the deposition of extended graphite layers, which, in combination with the possibility of nanostructuring anodic $\mathrm{TiO}_{2}$, provides a highly interesting functional material. Indeed, nanotubular $\mathrm{C} / \mathrm{TiO}_{2-x}$ composite layers, synthesized via the carbothermal route, have shown promising Li storage capacities, ${ }^{15}$ which may be further improved by means of an optimized synthesis, taking into account the crystallization characteristics of anodic films.

A detailed knowledge of local physico-chemical properties, as-obtained in this study, is important to understand the overall performance of functional materials. In view of the potential applications of $\mathrm{C} / \mathrm{TiO}_{2}$ composite materials in energy conversion and storage, the herein introduced planar $\mathrm{C} / \mathrm{TiO}_{2} / \mathrm{Ti}_{\text {poly }}$ composite is proposed as a model system for the investigation of propertyperformance relationships. Taking advantage of the substrate grain effect, two-dimensional property maps of the $\mathrm{C} / \mathrm{TiO}_{2}$ film that correlate (substrate grain dependent) intrinsic physico-chemical properties, such as chemical composition or morphology, and functional properties, such as electric conductivity, catalytic activity or (electro-)chemical stability, will give valuable information about the material. This can be realized by means of local analysis tools, such as SPEM $^{21}$ and micro-electrochemistry. ${ }^{58}$

\section{Author contributions}

The manuscript was written through contributions of all authors. CR planned and executed or coordinated the experiments, evaluated the data and drafted the manuscript. MF participated in the SPEM experiments and contributed to the SPEM data evaluation. CVV and LC participated in the SPEM experiments. NB evaluated the EBSD measurements which were performed by SJ. $\mathrm{CH}$ performed the Raman measurements. LG and MA gave technical support at the ESCAmicroscopy beamline of the Elettra Synchrotron in Trieste. SA conceived of the SPEM study and gave advice for the data evaluation. GG gave general advisory support. JKL supervised the study and actively participated in drafting the manuscript.

All authors have given approval to the final version of the manuscript.

\section{Funding sources}

The research of the manuscript was supported by funds of the EU RTD Framework Programme FP7 (FP7-NMP-2012-SMALL-6, project title DECORE, project number 309741).

\section{Conflicts of interest}

The authors declare no competing financial interest.

\section{Abbreviations}

UHV Ultra-high vacuum

EBSD Electron backscatter diffraction

AFM Atomic force microscopy

SEM Scanning electron microscopy

SPEM Scanning photoelectron microscopy

FWHM Full width at half maximum

NCG Nanocrystalline graphite 


\section{Acknowledgements}

The authors thank the EU RTD Framework Programme FP7 (FP7-NMP-2012-SMALL-6, project title DECORE, project number 309741) for financial support. We thank the DFG for financial support during the early stages of this study (project KU2398/1-1). Furthermore, the chair of Technical Chemistry II at TU München is acknowledged for the possibility for preliminary Raman studies, especially we are grateful to Jennifer Hein and Prof. Andreas Jentys for their assistance. We thank Prof. Kurt Hingerl for measuring the thickness of the anodic $\mathrm{TiO}_{2}$. We thank Dr Katrin F. Domke for the helpful discussions on the evaluation of Raman data.

\section{References}

1 L. Xiong and A. Manthiram, Electrochim. Acta, 2004, 49, 4163.

2 J. Tian, G. Sun, M. Cai, Q. Mao and Q. Xin, J. Electrochem. Soc., 2008, 155, B187.

3 P. V. Kamat, J. Phys. Chem. Lett., 2010, 1, 520.

4 T. Fröschl, U. Hörmann, P. Kubiak, G. Kučerová, M. Pfanzelt, C. K. Weiss, R. J. Behm, N. Hüsing, U. Kaiser, K. Landfester and M. Wohlfahrt-Mehrens, Chem. Soc. Rev., 2012, 41, 5313.

5 M. Dahl, Y. Liu and Y. Yin, Chem. Rev., 2014, 114, 9853.

6 W. Fan, Q. Lai, Q. Zhang and Y. Wang, J. Phys. Chem. C, 2011, 115, 10694.

7 B. Tryba, A. W. Morawski, T. Tsumura, M. Toyoda and M. Inagaki, J. Photochem. Photobiol., A, 2004, 167, 127.

8 Y. Zhang, Z.-R. Tang, X. Fu and Y.-J. Xu, ACS Nano, 2010, 4, 7303.

9 Y. T. Liang, B. K. Vijayan, O. Lyandres, K. A. Gray and M. C. Hersam, J. Phys. Chem. Lett., 2012, 3, 1760.

10 M. Favaro, S. Agnoli, C. Di Valentin, C. Mattevi, M. Cattelan, L. Artiglia, E. Magnano, F. Bondino, S. Nappini and G. Granozzi, Carbon, 2014, 68, 319.

11 A. Zana, C. Rüdiger, J. Kunze-Liebhäuser, G. Granozzi, N. E. A. Reeler, T. Vosch, J. J. K. Kirkensgaard and M. Arenz, Electrochim. Acta, 2014, 139, 21.

12 R. Hahn, F. Schmidt-Stein, J. Salonen, S. Thiemann, Y. Song, J. Kunze, V.-P. Lehto and P. Schmuki, Angew. Chem., Int. Ed., 2009, 48, 7236.

13 Y. Kado, R. Hahn and P. Schmuki, J. Electroanal. Chem., 2011, 662, 25.

14 C. Rüdiger, F. Maglia, S. Leonardi, M. Sachsenhauser, I. D. Sharp, O. Paschos and J. Kunze, Electrochim. Acta, 2012, 71, 1.

15 J. Brumbarov, J. P. Vivek, S. Leonardi, C. Valero-Vidal, E. Portenkirchner and J. Kunze-Liebhäuser, J. Mater. Chem. A, 2015, 3, 16469.

16 C. Rüdiger, J. Brumbarov, F. Wiesinger, S. Leonardi, O. Paschos, C. Valero Vidal and J. Kunze-Liebhäuser, ChemCatChem, 2013, 5, 3219.

17 L. Calvillo, G. García, A. Paduano, O. Guillén-Villafuerte, C. Valero-Vidal, A. Vittadini, M. Bellini, A. Lavacchi, S. Agnoli, A. Martucci, J. Kunze-Liebhäuser, E. Pastor and G. Granozzi, ACS Appl. Mater. Interfaces, 2016, 8, 716.
18 A. Aladjem, J. Mater. Sci., 1973, 8, 688.

19 P. Roy, S. Berger and P. Schmuki, Angew. Chem., Int. Ed., 2011, 50, 2904.

20 L. Calvillo, D. Fittipaldi, C. Rüdiger, S. Agnoli, M. Favaro, C. Valero-Vidal, C. Di Valentin, A. Vittadini, N. Bozzolo, S. Jacomet, L. Gregoratti, J. Kunze-Liebhäuser, G. Pacchioni and G. Granozzi, J. Phys. Chem. C, 2014, 118, 22601.

21 M. K. Abyaneh, L. Gregoratti, M. Amati, M. Dalmiglio and M. Kiskinova, e-J. Surf. Sci. Nanotechnol., 2011, 9, 158.

22 L. Gregoratti, A. Barinov, E. Benfatto, G. Cautero, C. Fava, P. Lacovig, D. Lonza, M. Kiskinova, R. Tommasini, S. Mähl and W. Heichler, Rev. Sci. Instrum., 2004, 75, 64.

23 H.-J. Bunge, Texture Analysis in Materials Science: Mathematical Methods, Butterworths \& Co, London, U.K., 2nd edn, 1982.

24 The lattice cell was drawn with the software Diamond 4.0 (demonstration version).

25 U. König and B. Davepon, Electrochim. Acta, 2001, 47, 149. 26 M. V. Diamanti, M. P. Pedeferri and C. A. Schuh, Metall. Mater. Trans. A, 2008, 39, 2143.

27 A. K. Sharma, Thin Solid Films, 1992, 208, 48.

28 S. Kudelka and J. W. Schultze, Electrochim. Acta, 1997, 42, 2817. 29 J. W. Schultze, B. Davepon, F. Karman, C. Rosenkranz, A. Schreiber and O. Voigt, Corros. Eng., Sci. Technol., 2004, 39, 45.

30 T. Ohsaka, F. Izumi and Y. Fujiki, J. Raman Spectrosc., 1978, 7, 321.

31 S. P. S. Porto, P. A. Fleury and T. C. Damen, Phys. Rev., 1967, 154, 522.

32 A. Mooradian and P. M. Raccah, Phys. Rev. B: Solid State, 1971, 3, 4253.

33 S.-W. Hsu, T.-S. Yang, T.-K. Chen and M.-S. Wong, Thin Solid Films, 2007, 515, 3521.

34 J. Zhang, M. Li, Z. Feng, J. Chen and C. Li, J. Phys. Chem. B, 2006, 110, 927.

35 A. C. Ferrari and J. Robertson, Phys. Rev. B: Condens. Matter Mater. Phys., 2000, 61, 95.

36 M. Favaro, S. Leonardi, C. Valero-Vidal, S. Nappini, M. Hanzlik, S. Agnoli, J. Kunze-Liebhäuser and G. Granozzi, Adv. Mater. Interfaces, 2015, 2, 1400462.

37 M. Fernández-García, X. Wang, C. Belver, J. C. Hanson and J. A. Rodriguez, J. Phys. Chem. C, 2007, 111, 674.

38 V. Likodimos, T. Stergiopoulos, P. Falaras, J. Kunze and P. Schmuki, J. Phys. Chem. C, 2008, 112, 12687.

39 F. D. Hardcastle, H. Ishihara, R. Sharma and A. S. Biris, J. Mater. Chem., 2011, 21, 6337.

40 H. Matsuura, M. Hiraishi and T. Miyazawa, Spectrochim. Acta, 1972, 2, 2299.

41 J. F. Mammone and S. K. Sharma, J. Phys. Chem., 1980, 84, 3130.

42 N. Ito, T. Fujiyama and Y. Udagawa, Bull. Chem. Soc. Jpn., 1983, 56, 379.

43 I. H. Boyaci, H. E. Genis, B. Guven, U. Tamer and N. Alper, J. Raman Spectrosc., 2012, 43, 1171.

44 D. Bersani, P. P. Lottici and X.-Z. Ding, Appl. Phys. Lett., 1998, 72, 73 . 
45 W. F. Zhang, Y. L. He, M. S. Zhang, Z. Yin and Q. Chen, J. Phys. D: Appl. Phys., 2000, 33, 912.

46 A. Li Bassi, D. Cattaneo, V. Russo, C. E. Bottani, E. Barborini, T. Mazza, P. Piseri, P. Milani, F. O. Ernst, K. Wegner and S. E. Pratsinis, J. Appl. Phys., 2005, 98, 1.

47 T. Ohsaka, J. Phys. Soc. Jpn., 1980, 48, 1661.

48 D. Regonini, A. Jaroenworaluck, R. Stevens and C. R. Bowen, Surf. Interface Anal., 2010, 42, 139.

49 B. Davepon, J. W. Schultze, U. König and C. Rosenkranz, Surf. Coat. Technol., 2003, 169-170, 85.

50 S. Kudelka, A. Michaelis and J. W. Schultze, Electrochim. Acta, 1996, 41, 863.

51 T. Tsumura, N. Kojitani, I. Izumi, N. Iwashita, M. Toyoda and M. Inagaki, J. Mater. Chem., 2002, 12, 1391.
52 M. Pfanzelt, P. Kubiak, U. Hörmann, U. Kaiser and M. Wohlfahrt-Mehrens, Ionics, 2009, 15, 657.

53 I. Eswaramoorthi and L.-P. Hwang, Diamond Relat. Mater., 2007, 16, 1571.

54 S. M. Jain, J. J. Biedrzycki, V. Maurino, A. Zecchina, L. Mino and G. Spoto, J. Mater. Chem. A, 2014, 2, 12247.

55 J. J. Biedrzycki, S. Livraghi, I. Corazzari, L. Mino, G. Spoto and E. Giamello, Langmuir, 2015, 31, 569.

56 G. Martra, Appl. Catal., A, 2000, 200, 275.

57 A. N. Patel, M. G. Collignon, M. A. O’Connell, W. O. Y. Hung, K. McKelvey, J. V. MacPherson and P. R. Unwin, J. Am. Chem. Soc., 2012, 134, 20117.

58 S. O. Klemm, J.-C. Schauer, B. Schuhmacher and A. W. Hassel, Electrochim. Acta, 2011, 56, 4315. 